\title{
Experimental study of CFRP strengthened steel columns subject to lateral impact loads
}

DOI:

10.1016/j.compstruct.2017.10.089

\section{Document Version}

Accepted author manuscript

Link to publication record in Manchester Research Explorer

\section{Citation for published version (APA):}

Kadhim, M. M. A., Wu, Z., \& Cunningham, L. S. (2018). Experimental study of CFRP strengthened steel columns subject to lateral impact loads. Composite Structures, 185, 94-104.

https://doi.org/10.1016/j.compstruct.2017.10.089

\section{Published in:}

Composite Structures

\section{Citing this paper}

Please note that where the full-text provided on Manchester Research Explorer is the Author Accepted Manuscript or Proof version this may differ from the final Published version. If citing, it is advised that you check and use the publisher's definitive version.

\section{General rights}

Copyright and moral rights for the publications made accessible in the Research Explorer are retained by the authors and/or other copyright owners and it is a condition of accessing publications that users recognise and abide by the legal requirements associated with these rights.

\section{Takedown policy}

If you believe that this document breaches copyright please refer to the University of Manchester's Takedown Procedures [http://man.ac.uk/04Y6Bo] or contact uml.scholarlycommunications@manchester.ac.uk providing relevant details, so we can investigate your claim.

\section{OPEN ACCESS}




\title{
Experimental study of CFRP strengthened steel columns subject to lateral impact loads
}

\author{
Majid M.A. Kadhim*(1), (2), Zhangjian Wu ${ }^{(1)}$, Lee S Cunningham ${ }^{(1)}$ \\ (1)School of Mechanical, Aerospace and Civil Engineering, The University of Manchester, \\ Manchester M13 9PL, UK \\ (2)College of Engineering, University of Babylon, Al Hillah, Iraq \\ * Corresponding author. E-mail addresses: majid.kadhim@ manchester.ac.uk (M. Kadhim) \\ jack.wu@manchester.ac.uk (Z.J. Wu)
}

lee.scott.cunningham@manchester.ac.uk (L.S. Cunningham)

\begin{abstract}
In both building and civil engineering structures, the occurrence of impact loading to column elements can be a significant issue, particularly in regard to disproportionate collapse. For existing structures vulnerable to impacts, the development of appropriate strengthening techniques is key to extending service life and improving robustness. In the case of structural steelwork, composites such as carbon fibre reinforced polymer (CFRP) offer a promising means of retrofitting and improving performance under impact. Towards this, the present study experimentally investigated a total of 12 square hollow section (SHS) columns under impact loads. The test series included both unstrengthened and CFRP strengthened samples with different fibre orientations with a view to finding the optimum CFRP configuration. As a means of simulating lateral impact on axially loaded elements, a purpose-built test rig was manufactured to apply a compressive preload to the samples prior to impact. Different preloading levels were applied to the samples before they were impacted transversely. The results show that the strengthening effectiveness increased with higher preloading level. The
\end{abstract}


average reduction in the transverse displacement for the strengthened columns tested under $70 \%$ preloading level was around $32 \%$ compared to the unstrengthened column while this value was about $22 \%$ for the columns tested without compressive preload.

Keywords: carbon fibre reinforced polymer, impact, strengthening, structural steel,

\section{Introduction}

Column elements in buildings, bridges and other types of structures are often vulnerable to several types of accidental action. According to EN 1991-1-7, Eurocode 1 [1], common impact sources can include collisions from road vehicles, forklift trucks, trains and ships. Two strategies have been suggested in this standard to design structures against accidental events. The first strategy is based on identifying accidental actions then designing the structure to have sufficient minimum robustness or preventing/reducing the action entirely. The second strategy is based on limiting the extent of localised failure by providing alternative load paths or by designing key elements to sustain notional accidental action. Where existing structures vulnerable to impact have not been previously designed for such loads e.g. due to age, change of use etc., appropriate strengthening techniques are necessary. In general, it has been shown from previous studies that carbon fibre reinforced polymer (CFRP) is promising material with regards to strengthening metallic structures. A significant amount of research has been conducted to investigate the behaviour of CFRP strengthened steel members. The majority of these studies are focused on the performance of strengthened members under static loading [2-5]. Although CFRP is a widely used structural material, potentially more economic, alternative composites such as glass fibre reinforced polymer (GRP) have been used in quasi-static applications on steelwork. Existing studies [6-8] have been undertaken to compare different strengthening schemes including using CFRP and GRP in the strengthening of steel beams under quasi-static loading rates. It is worth noting from 
this set of studies that the GRP plate, which was four times thicker than the CFRP plate, provided an increase in stiffness $25 \%$ lower than that provided by CFRP, while it was relatively more effective in increasing beam strength when compared to CFRP. The reduction in cost associated with GRP has to be offset against the increased material quantity required in order to gain strengthening effects commensurate with CFRP. In view of this, the present study will focus on the ability of the CFRP strengthening technique in enhancing steel structures under low-velocity impact.

To date, a relatively small number of studies have been conducted on the behaviour of CFRP strengthened metallic structures under impact loading [9-14]. Among these limited studies, Al-Zubaidy et al. focused on the bond characteristic between CFRP fabric and steel plate under impact loading by testing a series of double strap joints under different strain rates. The bond behaviour was investigated experimentally and numerically throughout these studies without considering the effect of impact loads on the structural members. Alam and Fawzia [12] and Kadhim et al. [13] investigated numerically the behaviour of CFRP strengthened steel columns. ABAQUS was employed in both studies in order to investigate the behaviour of CFRP strengthened columns subjected to impact loads. In the former study, it was found that the CFRP could minimise the transverse displacement of the impacted columns by more than $58 \%$. The assumption of perfect bond between CFRP and steel column was adopted. While in the latter study where the model accounted for potential de-bonding, the reduction in the transverse displacement was between $44 \%$ and $17 \%$ depending on CFRP configuration, preloading level and boundary conditions etc. Further to this, Kadhim et al. [14] examined the behaviour of CFRP strengthened steel I' section beams under impact loads using ANSYS. It was found that the CFRP was able to reduce the mid-span deflection by more than $11 \%$ compared to the unstrengthened beams. Up to now, little attention has been paid to the effect of impact loads on CFRP strengthened structural steel elements and no readily available 
previous study has investigated experimentally their performance under impact loads. The work presented in this paper therefore represents the first available study of its kind.

At the time of accidental load, structural members are usually under their normal service load. This co-existing service load (preloading) should be taken into account when examining the behaviour of a structural member under impact load [15]. The experimental study conducted by Zeinoddini et al. [15] found that the level of damage of tested un-strengthened columns was dependent on the level of axial preload. Al-Thairy [16] undertook an extensive numerical parametric study using the commercial finite element code ABAQUS to develop a simplified analysis method for axially compressed un-strengthened steel columns subjected to transverse impact. It was found that the location of the plastic hinge was almost always close to the centre of the column and was not dependent of the impact position except for a very low level of axial compression ( $<25 \%$ design resistance). Both aforementioned studies found that the axial compression load has a huge effect on the behaviour of steel columns subjected to impact loads.

In view of the aforementioned literature review, the primary aim of this paper is to explore experimentally the behaviour of CFRP strengthened axially loaded steelwork under transverse impact load. It is envisaged that the experimental data gathered will from a useful platform for further research, providing for the first time detailed validation case studies for those involved in the development of numerical models in this application. The experimental program was conducted by preparing a series of strengthened and unstrengthened samples. An overall of 12 samples were tested using a purpose-built test rig. The main challenge in design of this test rig was to maintain samples under compression preloading throughout application of impact to simulate the real situations for columns in structures. Different preloading levels were applied to the samples prior to impact with values of $0 \%, 50 \%$ and $70 \%$ of the ultimate design load, to find out the effect of the preloading level. In addition, 
three CFRP configurations were investigated including strengthening with fibres oriented in the longitudinal, transverse and both longitudinal and transverse directions with every preloading level to investigate the effect of the CFRP configuration.

\section{Test rig}

A purpose-built test rig was manufactured in the laboratory of the school of Mechanical, Aerospace and Civil Engineering at the University of Manchester. The test rig (schematic view shown in Fig. 1) was designed to be operated with a drop hammer in the dynamic laboratory which can drop $150 \mathrm{~kg}$ from a height of up-to $5 \mathrm{~m}$.

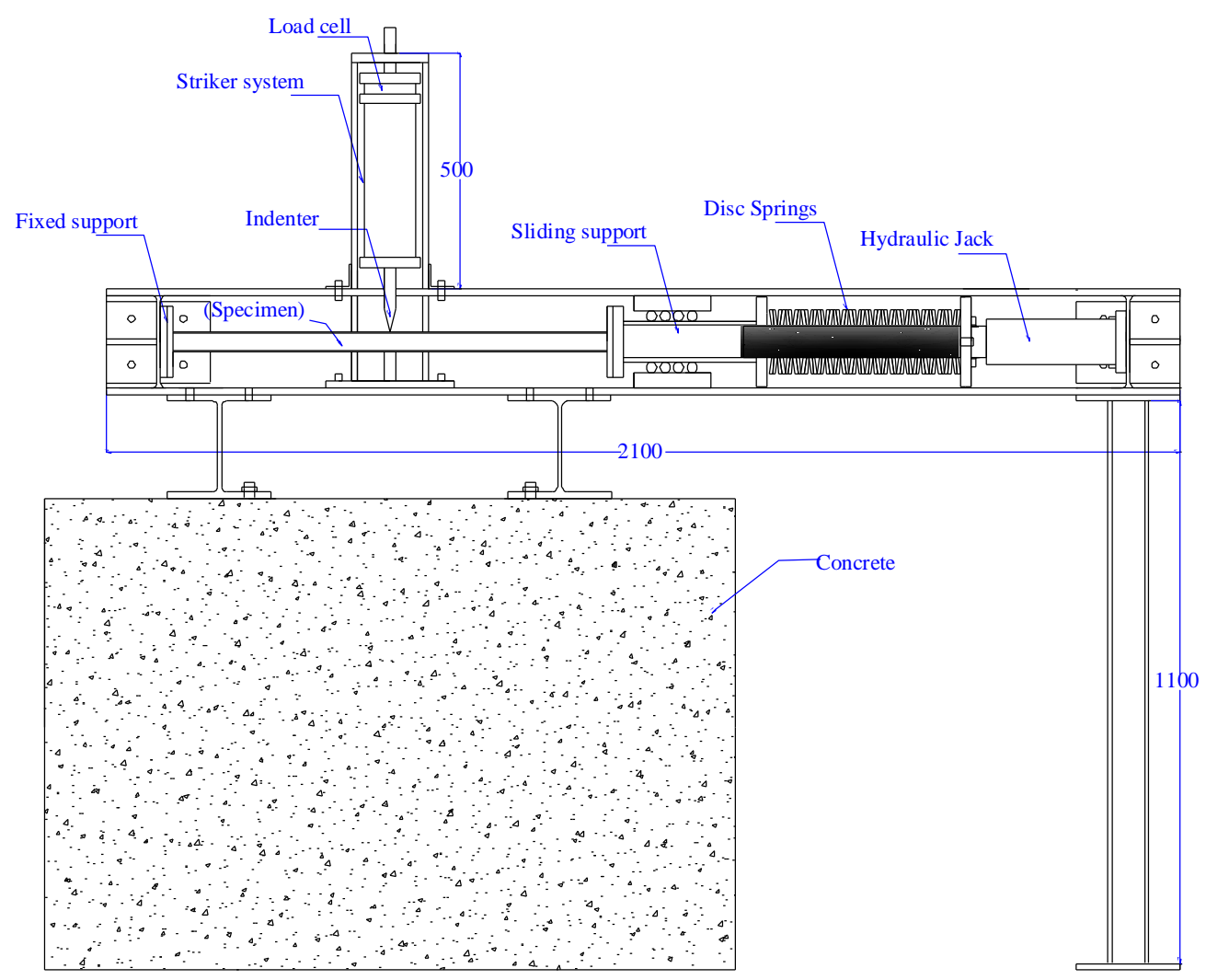

Fig. 1: Schematic view of the test rig

\subsection{Disc springs}


The main idea behind manufacturing this test rig was to create load and boundary conditions similar to columns in practice. Prior to and during impact, columns carry designed superimposed dead loads and all or part of designed live loads. However, after applying impact load in the laboratory, the specimens become laterally shorter. If the pre-compression load is applied using a hydraulic jack, it would be released as a result of the sequential shortening and the hydraulic system cannot react quickly to fill the gap (between the hydraulic system and the specimens) in the short durations associated with impact. In order to solve this problem, Zeinoddini et al. [15] employed disc springs to keep the load nearly constant during impact. In the present study, $125 \mathrm{~mm}$ outer diameter, $61 \mathrm{~mm}$ inner diameter, $6 \mathrm{~mm}$ thickness and $9.6 \mathrm{~mm}$ high disc springs were chosen to be stacked together in a $60 \mathrm{~mm}$ diameter shaft as shown in Fig. 2. The assembly of disc springs depends on the desired ultimate load and displacement. A combination of two parallel discs in series for these type of discs can provide more than $100 \mathrm{kN}$ load with about $65 \mathrm{~mm}$ displacement. The overall length of the pile of disc springs obtained from this arrangement was $375 \mathrm{~mm}$. The compression load on the springs was applied using a hydraulic jack.

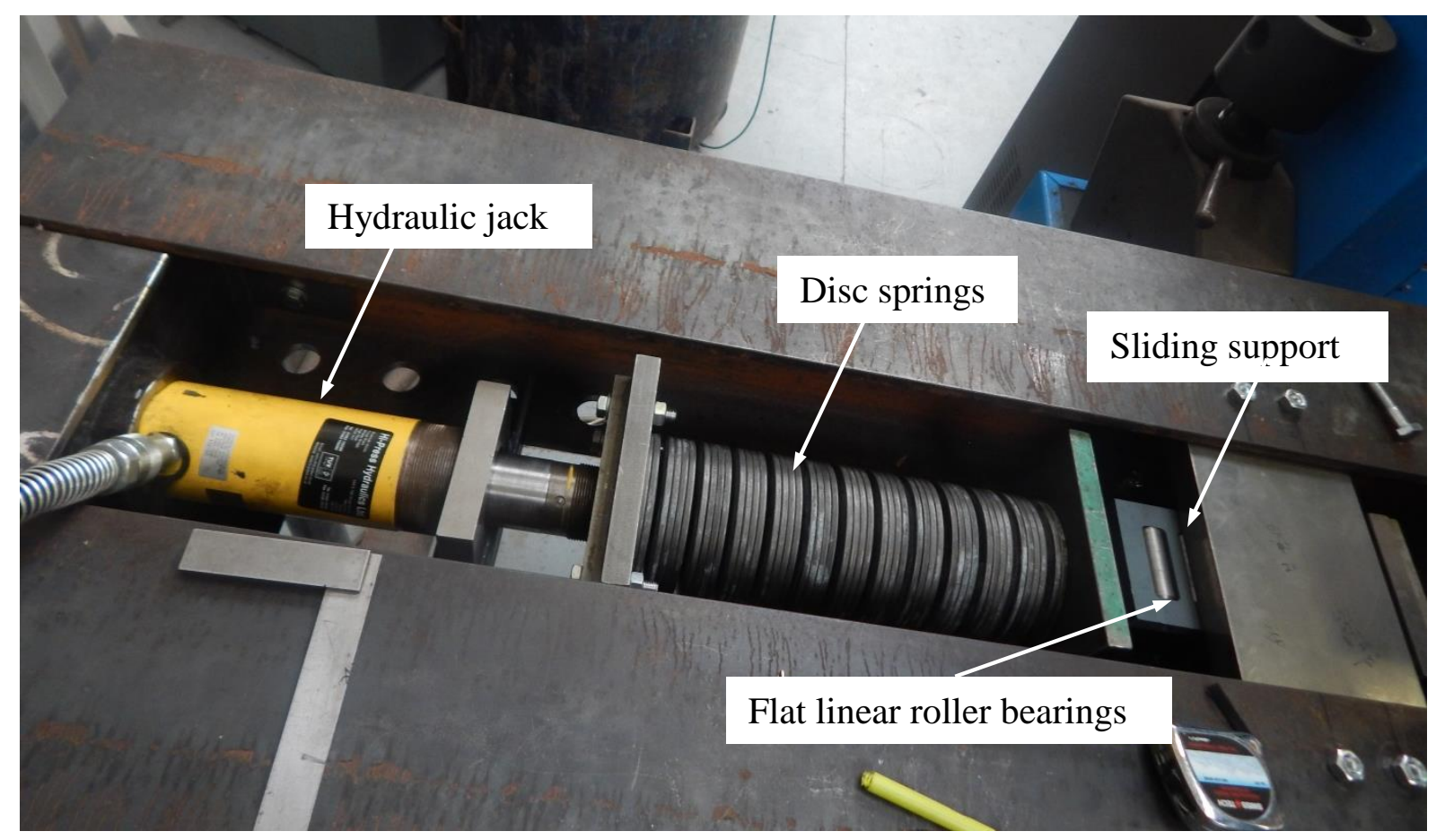


Fig. 2: View and details of axial loading system

\subsection{Striker system}

The striker system comprises four parts as shown in Fig. 3. The first part consists of two columns to support the guides, which are two $450 \mathrm{~mm}$ long stainless steel shafts. These shafts were supported vertically to guide the moveable part of the striker system. The second part is an indenter made from high strength steel (EN24). The head of the indenter was carefully rounded with a $2 \mathrm{~mm}$ radius to avoid local tearing in the specimens. The indenter was sufficiently welded to a $30 \mathrm{~mm}$ thick steel plate which has two holes at its ends. Two linear ball bearings were put in these holes to insure a low friction movement with the steel shaft guide as shown in Fig. 3 (b). The third part is a hollow circular section $100 \mathrm{~mm}$ in diameter (5mm wall thickness) and $300 \mathrm{~mm}$ long. This transfers the force from the fourth part to the indenter. The fourth component consists of two steel plates, which are completely similar to the plate in the second piece, used to hold a load cell. A $650 \mathrm{kN}$ capacity Kistler load cell was positioned between these steel plates under pre-compression to reduce the effect of vibration on the load cell.

\subsection{Supporting system}

This study aims to investigate the performance of specimens with one fixed and one sliding support. The supports allowed movements in the axial direction at one end, while the other directions were restrained from movements. The sliding support was created by making two flat linear roller bearings. These bearings were aligned under and above a rigid square section to obtain low friction movement in the axial direction. At one end of this square section, a $20 \mathrm{~mm}$ thick plate $(140 \times 140 \mathrm{~mm})$ with four holes was welded to connect the specimens while the other end, which had a $65 \mathrm{~mm}$ hole in the centre to allow the shaft of the disc springs pile 
to move inside the rigid square section, was welded to another steel plate to ensure the spring force transferred uniformly.

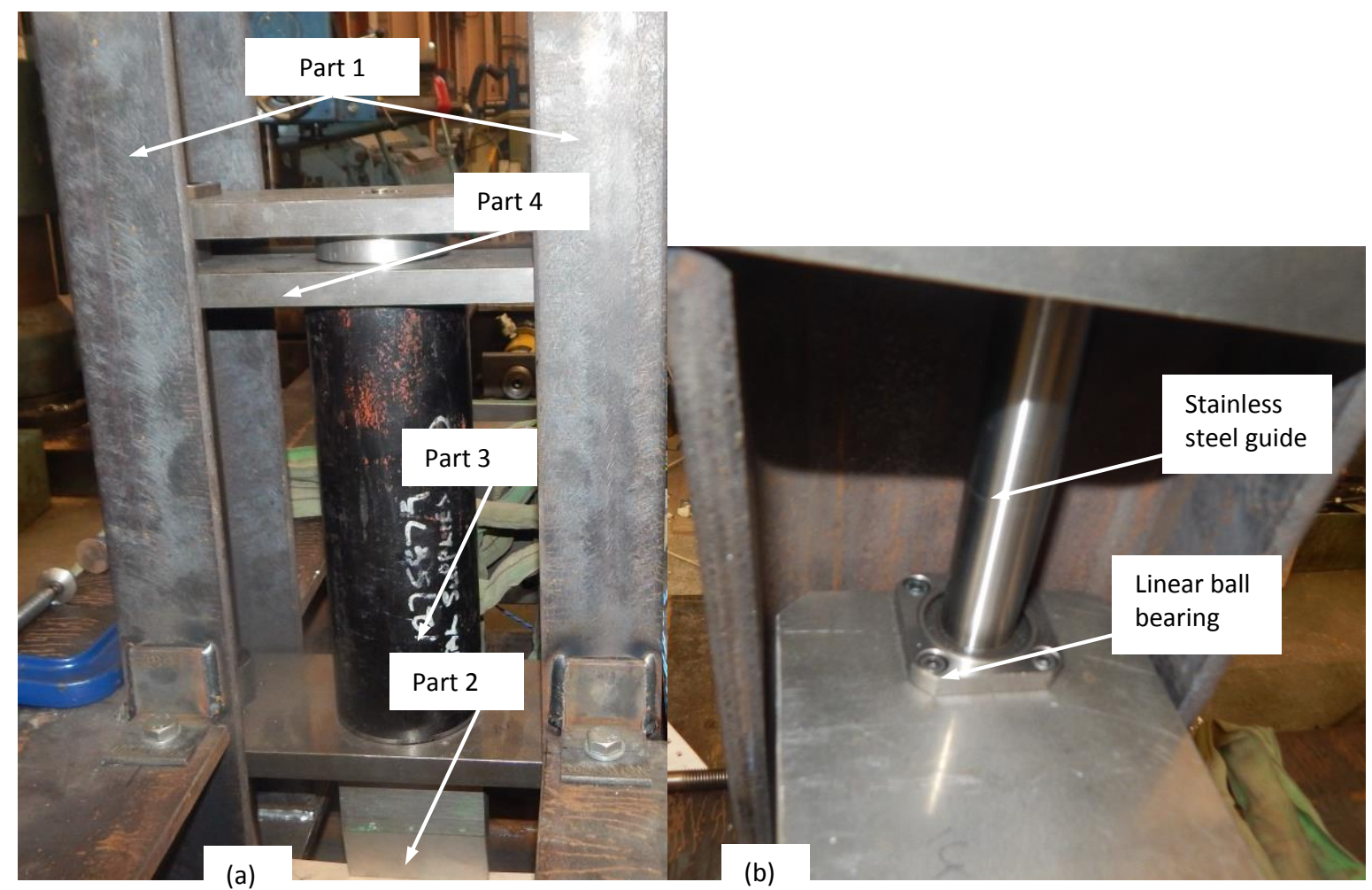

Fig. 3: View and details of striker system (a) striker system; (b) linear ball bearing

\section{Specimen preparation}

Each specimen was $850 \mathrm{~mm}$ in length and cut from a $4.2 \mathrm{~m}$ long Grade S355 cold-formed SHS $40 \times 40 \times 3$ steel section. Two end plates $(140 \times 140 \times 12 \mathrm{~mm})$ were carefully welded to the ends of the specimens as shown in Fig. 4 (a). Four holes had been drilled on these plates prior to welding to allow the samples to be bolted to the test rig.

\subsection{Steel specimens}

The proposed locations of strain gauges were cleaned carefully with acetone before applying abrasive action using sand paper to remove the weak surface layer. The specimens were then wiped again with acetone in order to attach strain gauges. $5 \mathrm{~mm}$ long post-yield strain gauges 
with $120 \Omega$ electrical resistance were affixed to the steel surface to measure the strain in the steel. Six strain gauges were mounted on the steel samples.

\subsection{CFRP strengthened steel specimens}

In the CFRP-to-steel interface, adhesion failure is much more likely to happen between adhesive material and steel rather than between adhesive material and CFRP. In order to avoid adhesion failure, special attention was given to surface preparations. Firstly, the steel surface is wiped with acetone to remove contaminants on the surface such as grease and oil. Mechanical abrasion using an abrasive wheel -which was efficiently used by other researchers such as Shaat [17] - is usually employed to remove the weak oxide layer and to roughen the surface for good adhesion. Next, the abraded surface is cleaned with acetone to remove any grease or oil before applying the CFRP layer as shown in Fig. 4 (b). The same surface treatment is recommended by adhesive material manufacturers e.g. [18]. At this stage, several post-yield strain gauges were affixed at certain locations. A special type of coating material (Nitrile rubber coating) was used to cover both the strain gauge and the terminal embedded under the CFRP layer. In this research, a wet lay-up technique [9] was used to fabricate the CFRP strengthened steel samples by bonding unidirectional carbon fibre sheet $0.6 \mathrm{~mm}$ thick made from Toho STS40 F13 24k using Araldite 420 adhesive. Carbon fibre sheets are then wiped with acetone to remove dust. A layer of Araldite 420 was applied on the steel surface using a brush. Efforts were made to ensure a uniform thickness of adhesive layer on all specimens. However, a $100 \%$ uniform adhesive layer thickness is impossible to achieve in practice by using the wet lay-up technique. This was followed by saturating a ply of carbon fibre sheet with the adhesive material using a brush before applying the saturated layer onto the adhesive-steel surface. A bristle roller was then used to eliminate small air bubbles and pin-holes. The same procedure was then used to add the second layers. The 
samples were cured at room temperature for at least a week as per the resin manufacturer's instructions. The $5 \mathrm{~mm}$ strain gauges were finally mounted on the CFRP surface.
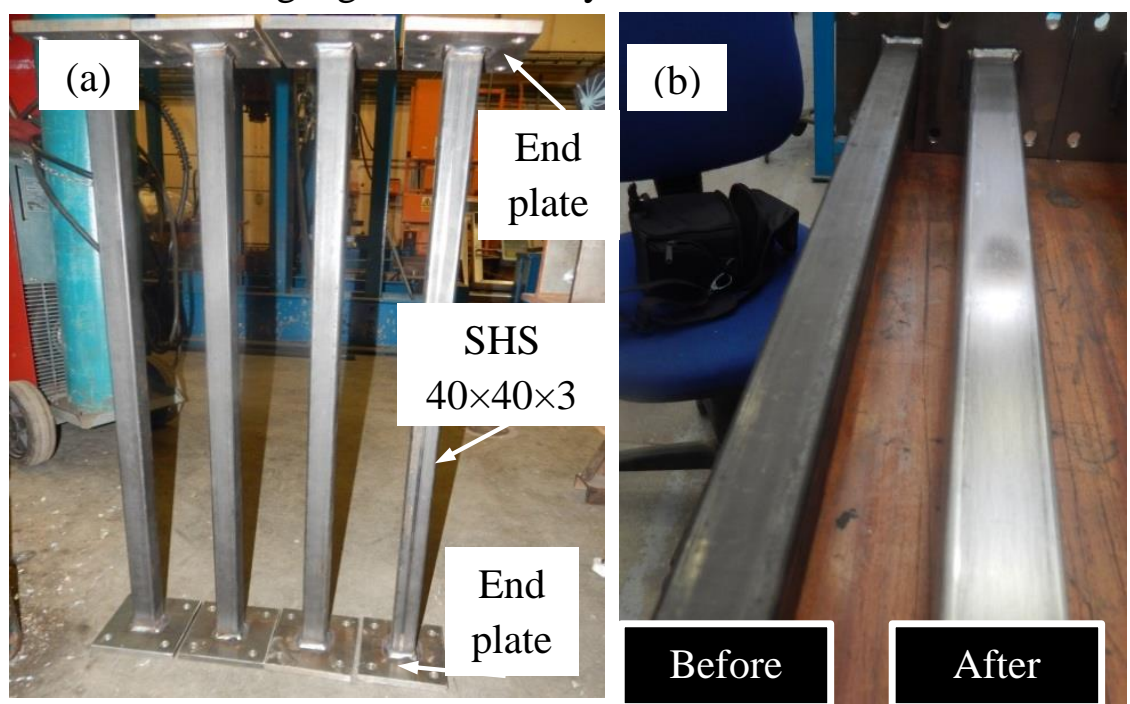

Fig. 4: (a) Samples view and details; (b) sample preparation

\section{Specimen configurations}

Overall, thirteen columns were tested under impact load as listed in Table 1. The mass dropped was $91 \mathrm{~kg}$ and the drop height was kept constant at $1 \mathrm{~m}$. All strengthened columns had CFRP wrapped around all four faces over the $800 \mathrm{~mm}$ length. For the samples strengthened with CFRP oriented in the transverse direction (CTT samples in Table 1) and with CFRP oriented in both of longitudinal and transverse direction (CLT samples in Table 1), the CFRP ply was wrapped in the transverse direction having $25 \mathrm{~mm}$ overlap to avoid premature failure. In each of the strengthened samples, the CFRP strengthening consisted of 2 plies, each with a thickness of $0.6 \mathrm{~mm}$. Each of the two plies were oriented either in the same direction (for the samples strengthened in the longitudinal direction and samples strengthened in the transverse direction) or in both directions (for samples strengthened in both directions). In other words, the overall thickness and mass of the CFRP strengthening was kept constant (1.2 mm in total) for all strengthened samples in all configurations in order to verify the effectiveness of each configuration. 
The thickness of adhesive material was measured using a $+/-0.01 \mathrm{~mm}$ accuracy Vernier gauge after preparing the samples. It was found that the average thickness of adhesive layer was $0.88 \mathrm{~mm}$ with $+/-0.2 \mathrm{~mm}$ along sample span. The samples were cured for 2 to 4 weeks before testing. The detailed information of each column sample is showed in Table 1. The following name system is employed to characterise each sample: the first letter (C) stands for the column, the second pair of letters (LL, TT or LT) denotes the orientation of fibres in each of the two CFRP layers used to strengthen the sample i.e. longitudinal, transverse and both longitudinal and transverse directions, respectively, and the last numeric value 0,50 and 70 denotes the preloading level (percentage) which is equal to applied load divided by the ultimate design load for the column [1]. For example, CLL50 means that the column was strengthened with 2 layers of CFRP with fibres oriented in the longitudinal direction and tested under transverse impact load while $50 \%$ preloading was applied.

Table 1: Identification and results of the tested specimens

\begin{tabular}{|c|c|c|c|c|c|c|c|}
\hline No. & $\begin{array}{c}\text { Specimen } \\
\text { label }\end{array}$ & $\begin{array}{c}\text { Preloading } \\
\text { level }(\%)\end{array}$ & $\begin{array}{c}\text { Fibre } \\
\text { orientation } \\
\text { force } \\
(\mathrm{kN})\end{array}$ & $\begin{array}{c}\text { Peak } \\
(\mathrm{Sec})\end{array}$ & $\begin{array}{c}\text { Duration } \\
*(\mathrm{kN})\end{array}$ & $\begin{array}{c}\text { Plateau } \\
\text { displacement } \\
(\mathrm{mm})\end{array}$ \\
\hline 1 & C0 & 0 & - & 152 & 0.0285 & 24.6 & 1.2 \\
\hline 2 & CLL0 & 0 & Longitudinal & 167.7 & 0.0275 & 24.7 & 3.1 \\
\hline 3 & CTT0 & 0 & Transverse & 152.4 & 0.0278 & 24.7 & 0 \\
\hline 4 & CLT0 & 0 & Both & 183.2 & 0.0280 & 25.4 & 0 \\
\hline 5 & C50 & 50 & - & 157.1 & 0.0318 & 19.3 & 3.4 \\
\hline 6 & CLL50 & 50 & Longitudinal & 170.2 & 0.0286 & 21.6 & 4.6 \\
\hline 7 & CTT50 & 50 & Transverse & 163 & 0.0301 & 21.9 & 1.1 \\
\hline 8 & CLT50 & 50 & Both & 145.9 & 0.0290 & 23.2 & 1.8 \\
\hline 9 & C70 & 70 & - & 180.9 & 0.0381 & 16.1 & 4.5 \\
\hline 10 & CLL70 & 70 & Longitudinal & 163.1 & 0.0314 & 20.1 & 6.5 \\
\hline 11 & CTT70 & 70 & Transverse & 154.4 & 0.0327 & 19.5 & 1.8 \\
\hline 12 & CLT70 & 70 & Both & 154.4 & 0.0308 & 21.1 & 2.9 \\
\hline
\end{tabular}

*Plateau defined in section 6.1 


\section{Test setup and instrumentation}

As previously mentioned, six strain gauges (or five for the samples strengthened with fibres oriented in the transverse direction) were mounted on every specimen as shown in Fig. 5. For the CFRP strengthened steel samples, three strain gauges were fixed to the steel surface and three (or two for the samples strengthened with fibres oriented in the transverse direction) fixed to the CFRP surface. For the samples strengthened with fibres oriented in the transverse direction, two strain gauges were attached on the CFRP surface parallel to the fibre direction. Linear Variable Displacement Transducers (LVDT) were positioned on the sliding end to measure the shortening in axial direction during the test. Displacement via time was measured using a digital video camera operating at 240 frame/sec. The pre-compression force was applied using the hydraulic jack fixed in the test rig as described in section 2 . The hydraulic jack pushes the steel shaft (inside disc springs) into the rigid hollow section inside the sliding support. This process compressed the disc springs which apply axial load to the specimen. The axial load was measured using the pressure meter in the pump which had been calibrated prior to the tests.

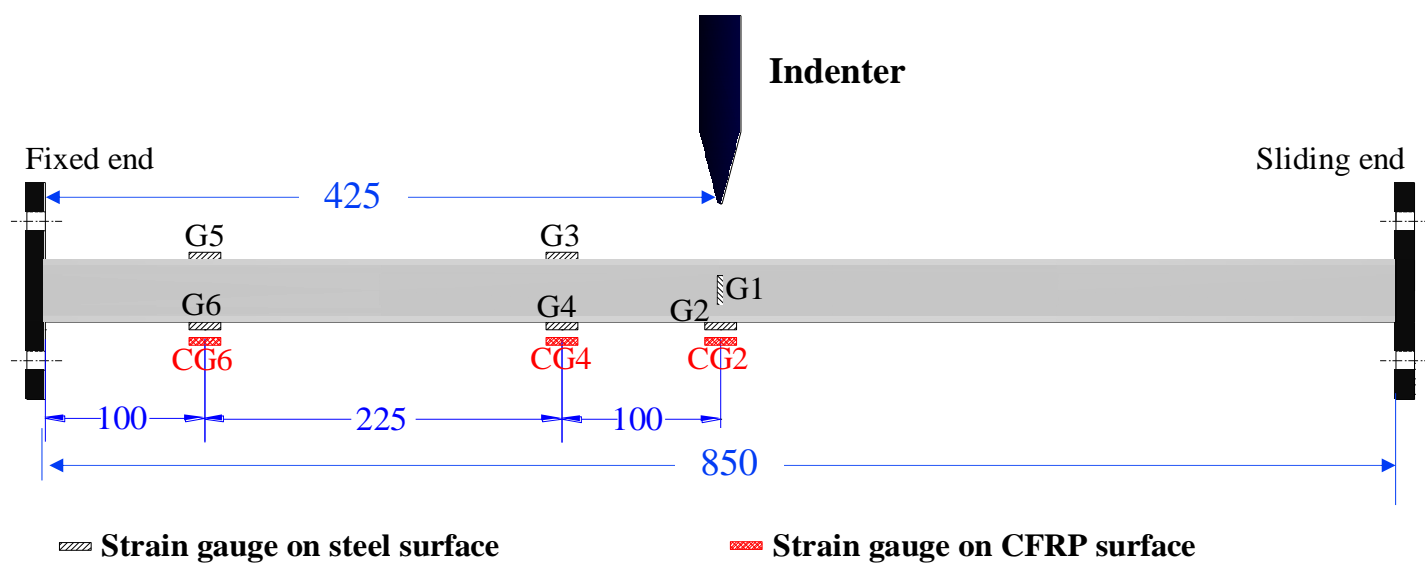

Fig. 5: Strain gauge positions

\section{Results and discussion}




\subsection{Load-time history}

The most important data recorded during the impact test is the impact force. A typical impact force-time history (as shown in Fig. 6) can be divided into three stages, i.e. peak stage: in which the force reaches a peak value in a short time when the mid-span of the sample has reached the velocity of the impactor then the curve descends to zero when the specimen and the impactor are separated. Then, the impactor hits the specimen a second time but with a smaller value. This process of striking and rebounding is repeated several times until the impact force becomes nearly constant when the second stage commences which is referred to henceforth as the plateau or mean impact force stage. In this stage, most of the impact energy is dissipated. Finally, the curve goes into the unloading stage and reaches zero gradually as the impact energy is dissipated.

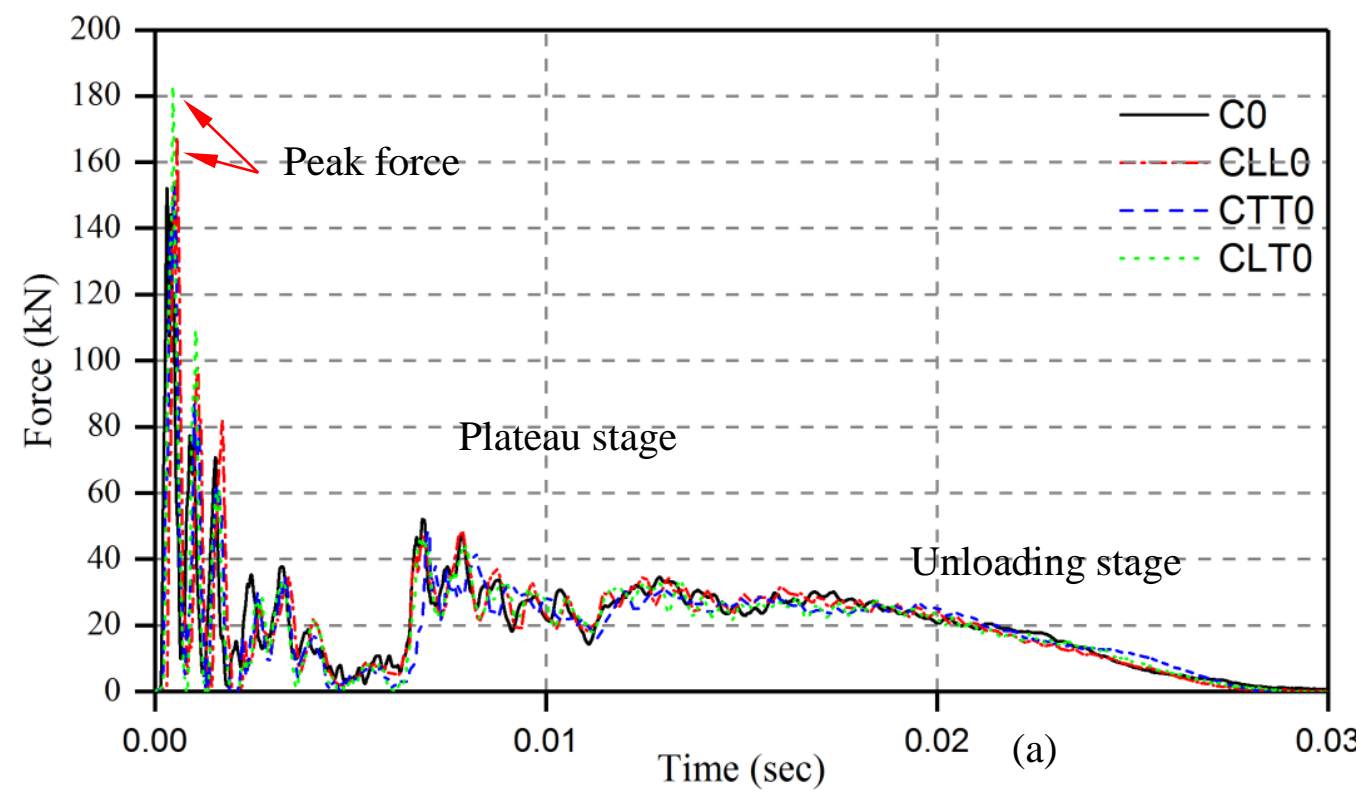



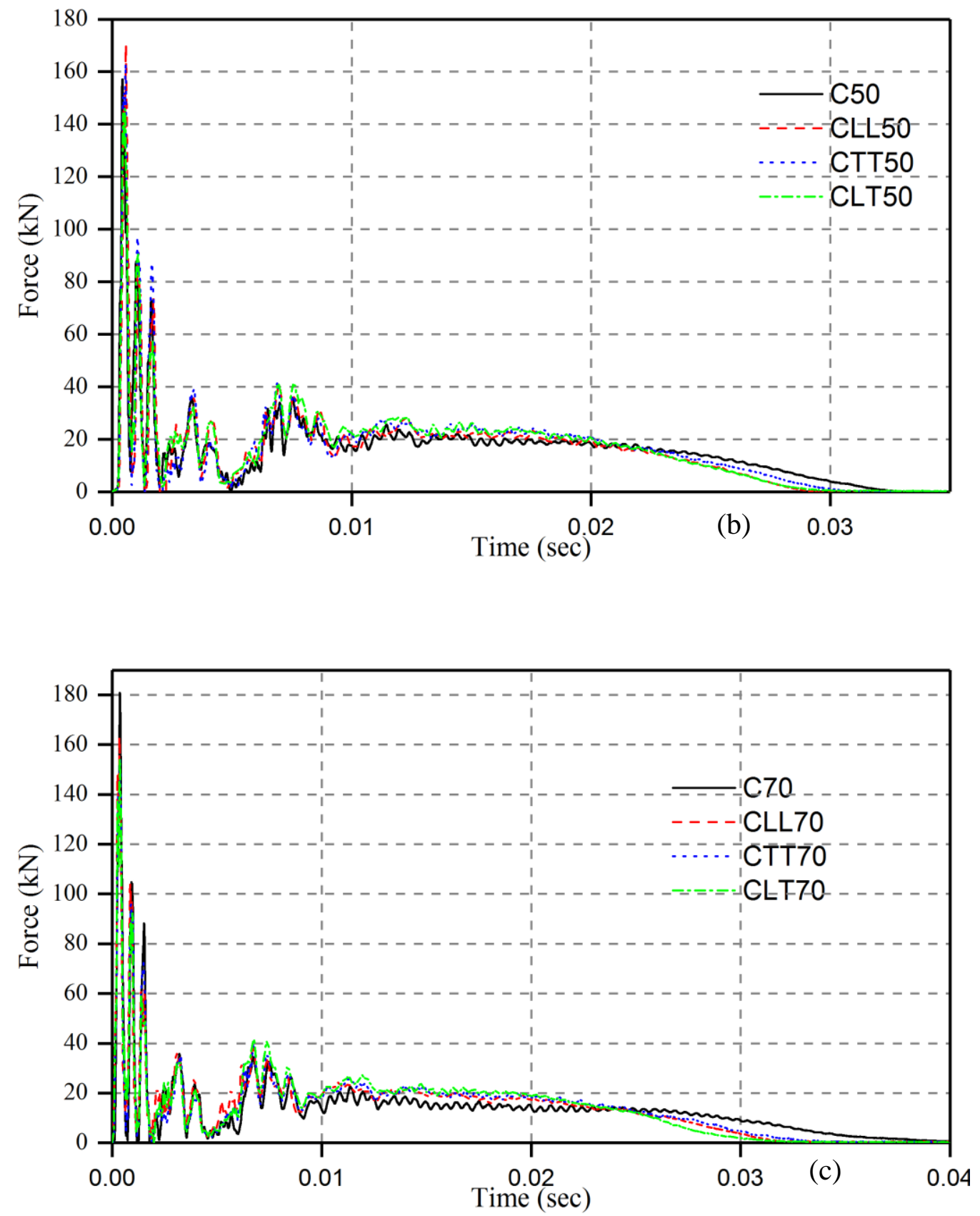

Fig. 6: Force-time history; (a) 0\% preloading, (b) 50\% preloading, (c) 70\% preloading

Fig. 7 shows the impact force against transverse displacement for specimen $\mathrm{C} 0$. The same stages can be seen in this figure regarding the peak impact and plateau stages while there is a slight difference in the shape of the unloading stage. 


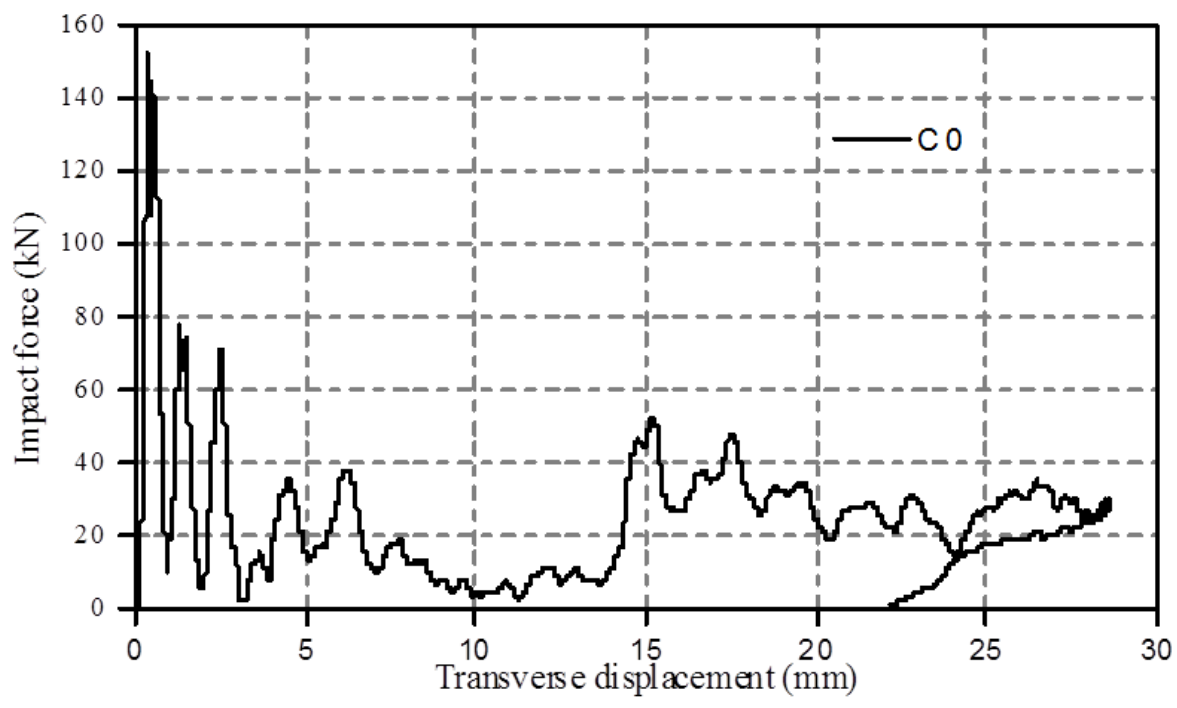

Fig. 7: Impact force- transverse displacement for specimen $\mathrm{C} 0$

\subsubsection{Peak force}

All samples were tested under the same impact mass and velocity. It can be seen in Fig. 8(a) that the peak force increased with high preloading levels for unstrengthened columns. Regarding the strengthened columns, there is no obvious trend for the rest of the samples, this may be due to the fact that the outer surface of the CFRP was not completely uniform as a result of using the wet lay-up technique which affects the initial force value.

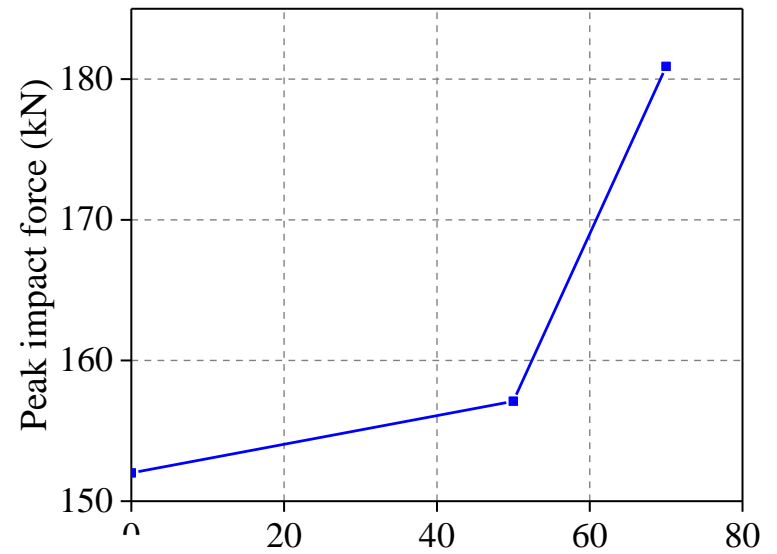

(a)

Preloading level (\%)

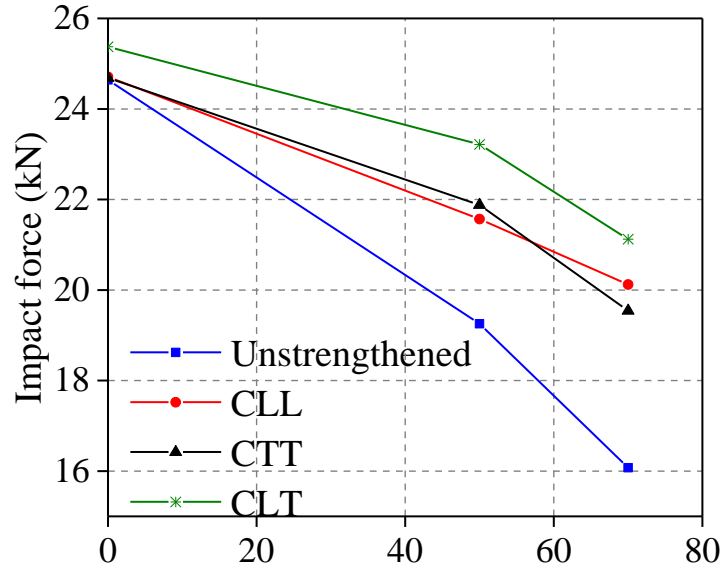

(b) Preloading level (\%)

Fig. 8: (a) peak impact force against different preloading levels for unstrengthened columns,

(b) plateau against different preloading levels and CFRP configurations. 


\subsubsection{Plateau stage}

During the plateau stage most of the impact energy is dissipated because it is a relatively long period compared to other stages of impact-time history. The plateau value for each specimen was based on the average impact force during the time after the peak stage until the unloading stage, which represents the plateau stage as previously defined in this section. Fig. 8(b) reveals that there was a slight increase in the plateau value as a result of using CFRP for samples under $0 \%$ preloading. This improvement in the plateau value was increased for higher levels of preloading load, i.e. the average increase in the plateau value for strengthened columns under $0 \%$ preloading level was about $1 \%$, while this value increased to 15 and $26 \%$ for 50 and $70 \%$ preloading levels respectively. The reason why the CFRP strengthened samples exhibit greater improvement with high preloading levels is related to the fact that the CFRP is more effective with higher applied work. A similar trend was observed in other studies such as $[13,19]$. This is thought to be caused mainly by increasing the plastic deformation in the impacted member. It is well known that the elastic moduli of both materials (steel and CFRP) are relatively similar. However, when steel sections undergo severe plastic deformation the tangent modulus of steel becomes small compared to the elastic modulus of CFRP; therefore, the role of CFRP becomes more significant.

In terms of the CFRP configurations, fibres oriented in both longitudinal and transverse directions was the most effective compared to other strengthening schemes, for example CLT70 had a plateau value $31 \%$ more than C70 while the plateau value for CLL70 and CTT70 increased 25 and $21 \%$ respectively compared to corresponding unstrengthened column.

\subsubsection{Impact duration}


The duration required to dissipate the impact energy (the overall period of the contact between the impactor and the specimen) is different depending on the preloading level and CFRP configuration and impact velocity. Generally, the impact duration is several times longer than the main natural period of the specimen because the natural period of the specimen depends on it's equivalent mass and stiffness. In the case of the impact duration, the period depends on the total mass, which consists of the equivalent mass of the specimen and the impactor together [15]. Regarding the preloading level, with high preloading levels the impact duration became longer which is consistent with the above definition of the impact duration because higher preloading caused reduction in the specimens' stiffness [15] (Fig. 9). Zeinoddini et al. [15] found experimentally that the first natural frequency decreased with an increase in the axial load level, indicating that the increase in the preloading level causes a reduction in the stiffness of the specimen. On the other hand, strengthening with CFRP led to an increase in the stiffness and a reduction in the impact duration with different values depending on the configuration. It can also be noticed from Fig. 9 that the column strengthened with fibres oriented in both longitudinal and transverse directions had a shorter impact duration compared to other configurations. 


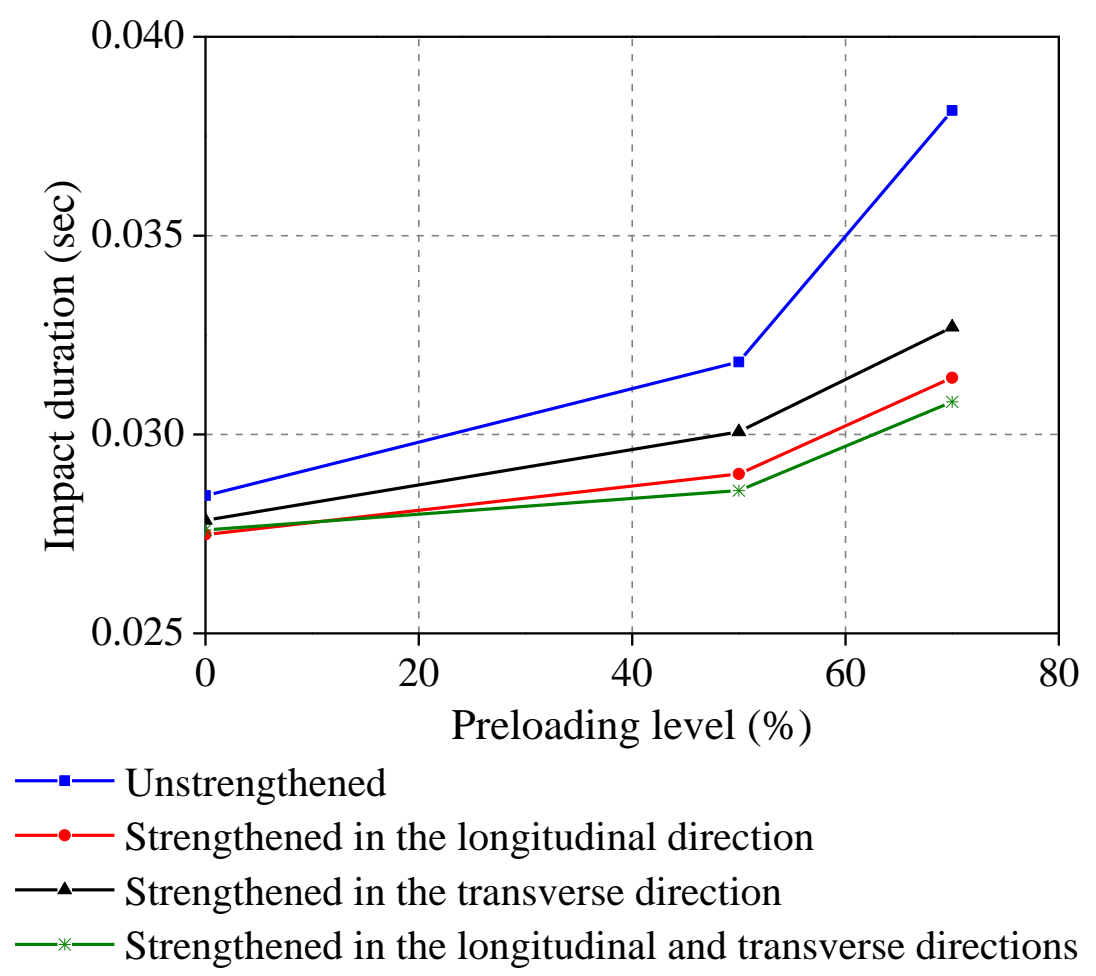

Fig. 9 : Impact duration against different preloading levels,

\subsection{Displacement-time history}

It can be concluded from Fig. 10(a) which shows the displacement-time history for the columns under $70 \%$ preloading that the column strengthened with fibres oriented in both directions had the lowest transverse displacement with $29 \%$ less than the unstrengthened column while the strengthened columns CLL70 and CTT70 had 19\% and 16\% less than the unstrengthened column (C70), respectively. This trend seems to be identical to that described in the previous section where the plateau for CLT70 was $31 \%$ more than corresponding value for the unstrengthened column (C70) and the plateau value for CLL70 and CTT70 was 25 and $21 \%$ more than the corresponding value for the unstrengthened column respectively. It can be noticed from Fig. 10 (b) that the transverse displacement increased with preloading levels and the starting time of the unloading stage is clearly different for each preloading level as described in section 6.1.3. 


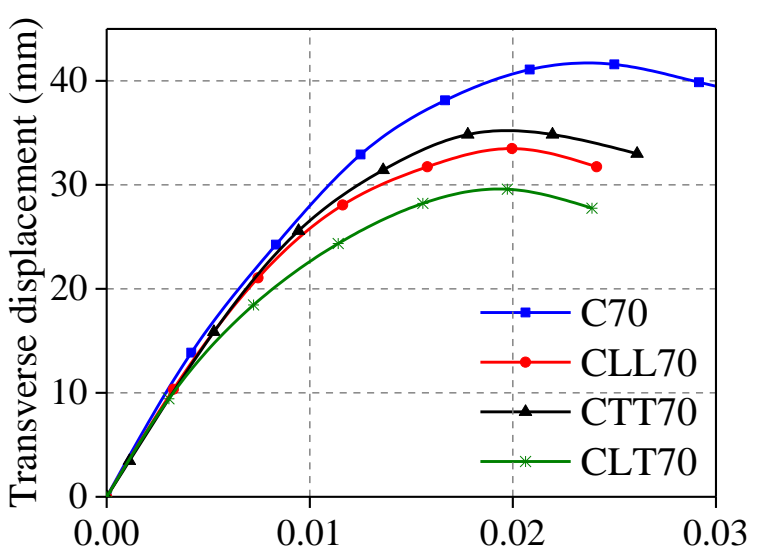

(a)

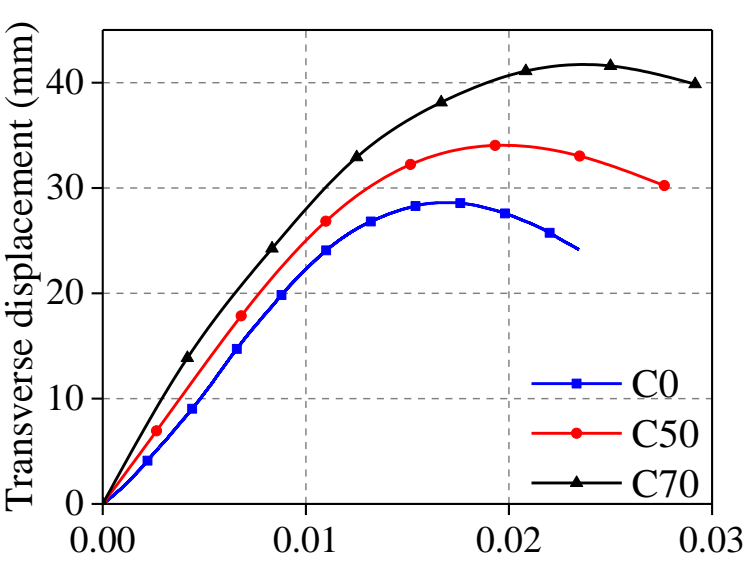

(b)

Time (sec)

Fig. 10: Transverse displacement against time; (a) 70\% preloading, (b) unstrengthened columns

\subsection{Residual deformation}

The residual deformation was measured for all tested samples using a LVDT with +/$0.001 \mathrm{~mm}$ accuracy. Note that residual deformations are referred to here as the final permanent deflection after impact. The deformed shape was measured along the top and bottom faces of the columns with one reading every $10 \mathrm{~mm}$ at mid-span and $100 \mathrm{~mm}$ in the rest of the columns, whereas the lateral deformation was measured only at the mid-span every $10 \mathrm{~mm}$. In general, when no preloading was applied, the residual displacement was small, and the effect of the CFRP became more significant when the preloading increased to $50 \%$ or 70\%. It can be seen from Fig. 11 that the strengthened columns always displayed less transverse displacement along their spans compared to the corresponding unstrengthened columns. For the specimens tested without preloading, the fibres oriented in the longitudinal direction was slightly more effective than other strengthening configurations but with greater local damage at mid-span. A comparison of residual deformed shape for other preloading levels (50\% and 70\%) showed that the fibres oriented in both longitudinal and transverse directions had the minimum residual transverse displacement along columns compared to the 
corresponding strengthened columns. A similar trend can be seen in Fig. 11 (b) in which the transverse displacement of the bottom face plotted against columns height.

The reduction in the cross-sectional depth of the columns at mid-span can be calculated using Fig. 11 (a) and Fig. 11 (b), this is represented by the difference between the maximum displacement value from Fig. 11 (a) and the maximum displacement value from Fig. 11 (b) divided by the original cross-sectional depth. It has been found, for instance, for the columns tested under $50 \%$ preloading that the reduction values were $12.1 \%$ for the unstrengthened column (C50) and 8.1\%, 5.1\% and 5.6\% for samples CLL50, CTT50 and CLT50 respectively. Clearly, the depth of the cross section has a significant effect on the momentcarrying capacity of the section, it would be expected that the reduction in the cross-sectional depth leads to a reduction in the load-carrying capacity of the section. Consequently, these percentages indicate that the CFRP arrangement achieved one of the main goals of strengthening, which is to control the reduction in the cross-sectional depth by minimising the local deformation and thus improving the load-carrying capacity of the members. In addition, it can also be concluded from these percentages that the samples strengthened with fibres oriented in the transverse direction had the best effectiveness in controlling the reduction in the cross-sectional depth compared to the others. 

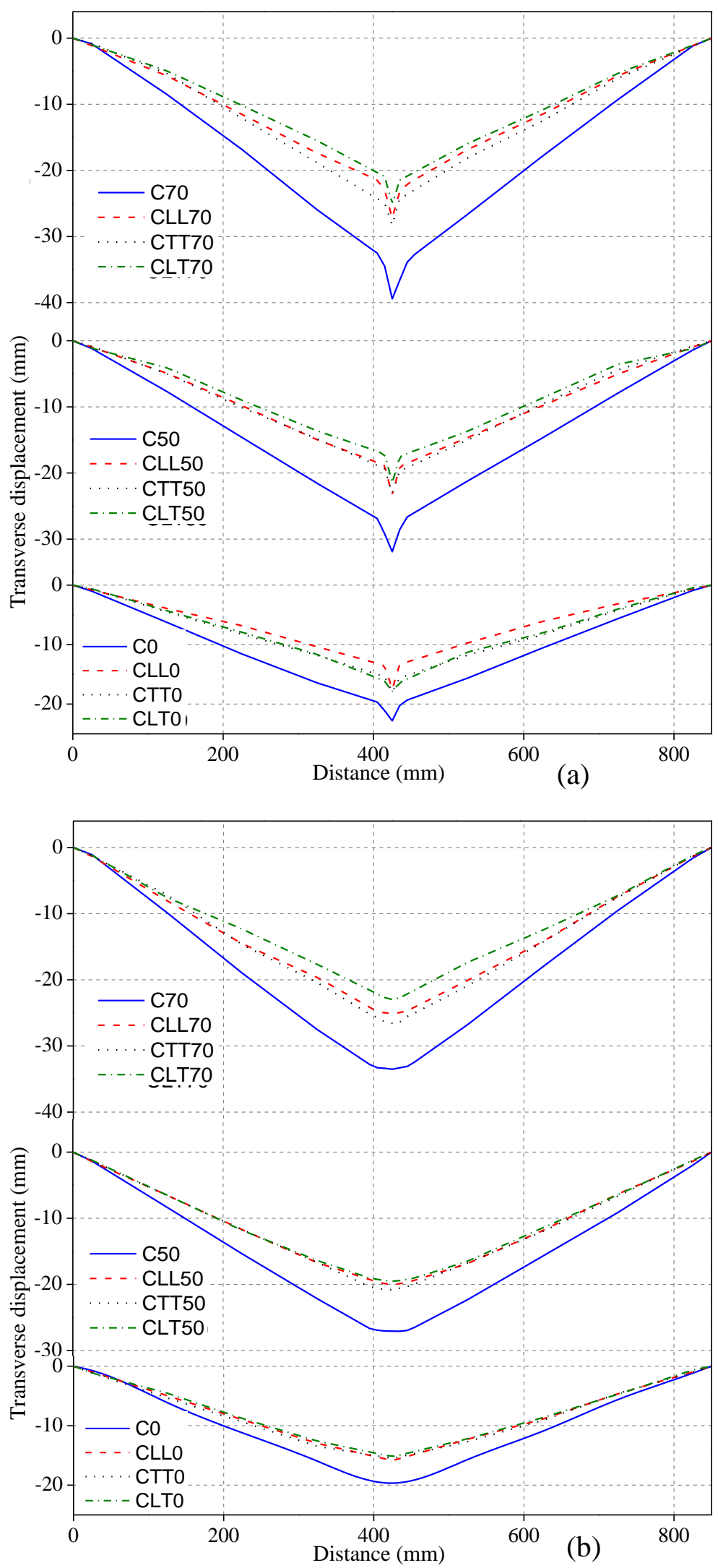

Fig. 11: Transverse residual displacement along the (a) top and (b) bottom faces of the columns 
Regarding lateral buckling, it can be found from Table 1 that, with an increase of the preloading level, the residual lateral displacement at the mid-span of the specimens increased. No lateral displacement in the columns strengthened with fibres oriented in the transverse direction under $0 \%$ preloading level was found. However, for CLL0, the lateral displacement increased compared to a corresponding value for the unstrengthened sample $(\mathrm{C} 0)$. Generally, the columns strengthened with fibres oriented in the transverse direction had the better performance in reducing the residual lateral displacement compared to the other strengthening configurations. This observation is consistent with what has been discussed in the previous section. A similar trend can be observed for the other preloading levels.

Based on the aforementioned discussion, using fibres oriented in the transverse direction had a significant effect on controlling the local deformations, which led to improved loadcarrying capacity. This observation is found to be consistent with that observed in previous studies conducted on CFRP strengthened steel columns under static load ,e.g., Shaat [17]. In contrast, fibres oriented in the longitudinal direction can improve the global behaviour of strengthened members. It seems that using fibres in both longitudinal and transverse directions can improve both global and local buckling resistance of strengthened members and, since the impacted member normally undergoes large displacement which is accompanied by heavy local deformations, fibres oriented in both longitudinal and transverse directions have the best performance compared to the other strengthening configurations.

\subsection{Failure Modes}

The failure modes observed in the experiment varied depending on the CFRP configurations and the preloading level. However, for the unstrengthened columns severe local buckling was experienced on the top face and side walls (webs) of the mid-span especially for the column with $70 \%$ preloading. The indentation was less severe for the samples strengthened with 
fibres oriented in the transverse direction as a result of the lateral confinement of the CFRP for the steel side walls. It can be seen from Fig. 12 that the columns strengthened with fibres oriented in the longitudinal direction had severe local buckling at the impact zone and the CFRP did not reduce the local buckling. Regarding the outer CFRP layer, no CFRP rupture or debonding occurred during all tests, in some cases compressive crushing of the CFRP was initiated locally at the impact region. 

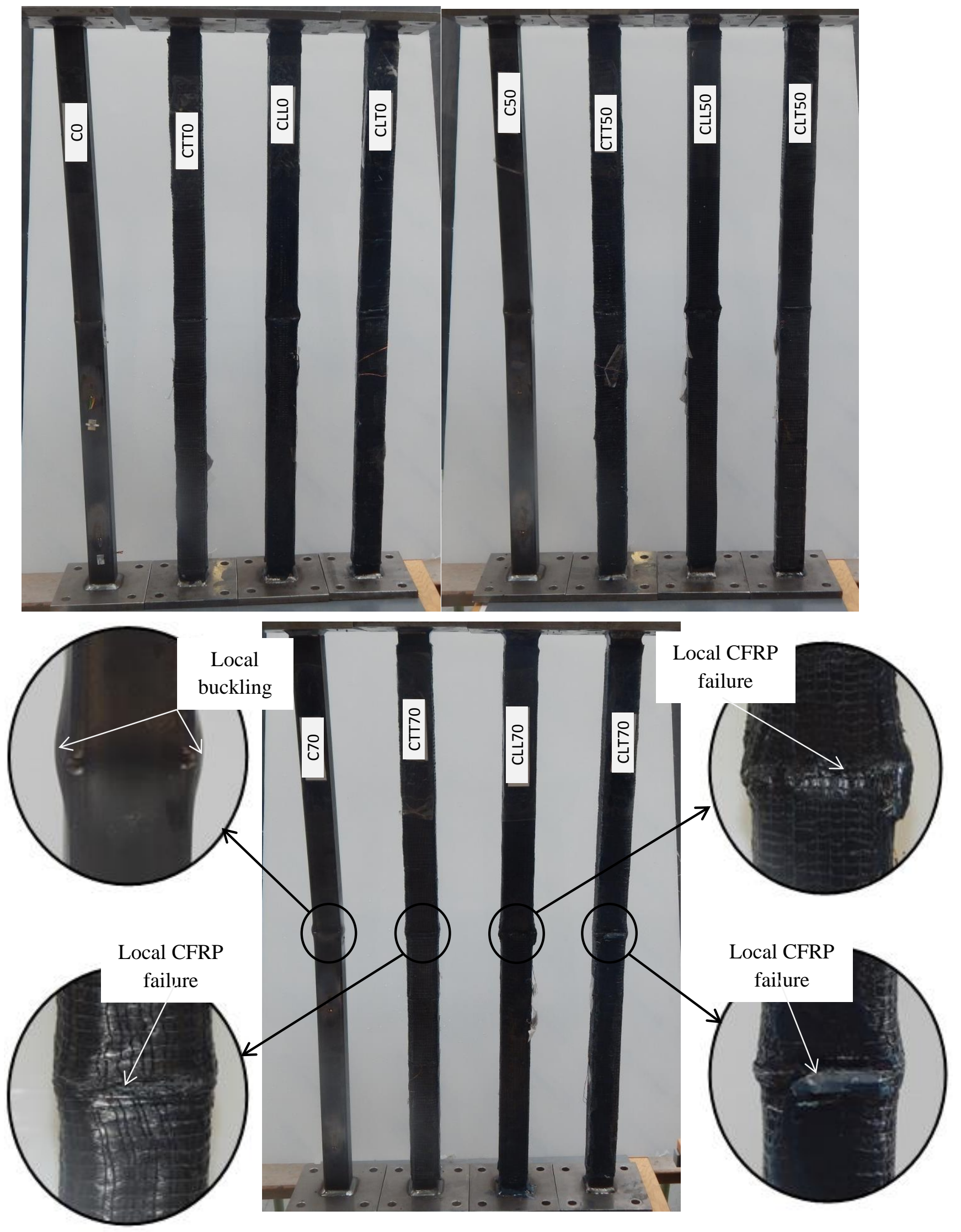

Fig. 12: Failure modes of the tested specimens. 


\subsection{Strain development}

As mentioned in section 5, six strain gauges were mounted in each sample (or five for samples strengthened with fibres oriented in the transverse direction). In this section, only the key results from the strain gauge readings which reflect the role of each strengthening configuration will be presented. The output form strain gauge (G1) for specimens under $70 \%$ preloading level demonstrates that the fibres oriented in the transverse direction can reduce local buckling for the strengthened members as shown in Fig. 13 (a). On the other hand, the output from strain gauge $(\mathrm{G} 2)$ positioned in the bottom face of the mid-span showed the opposite trend, i.e. the columns strengthened with fibres oriented in the longitudinal direction reduced the strain at this point to approximately half of the value in the unstrengthened column (Fig. 13 (b)). This is evidence that the fibres oriented in the longitudinal direction can improve global buckling for the strengthened columns. This observation is similar to those reported by [4] who investigated the effectiveness of CFRP on the SHS steel columns under static load.

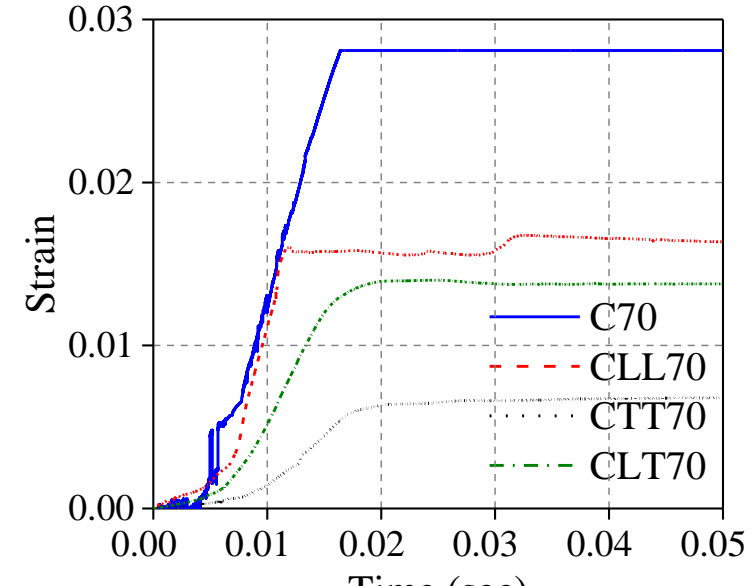

(a) Time (sec)

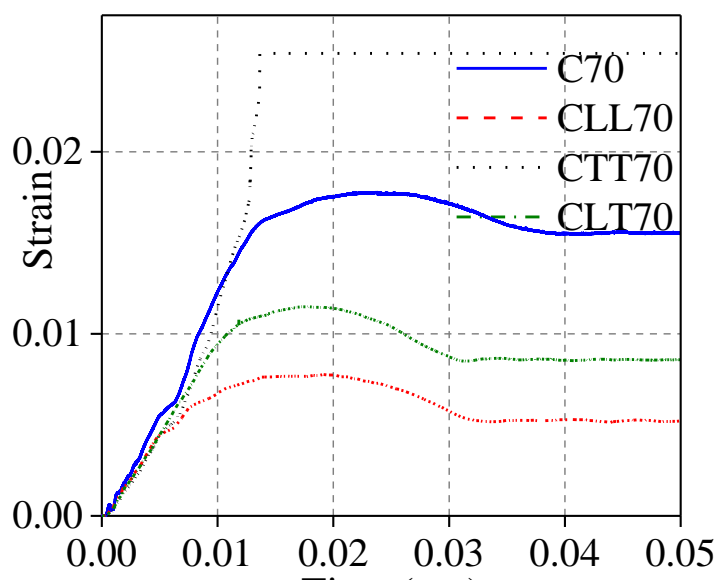

(b) Time (sec)

Fig. 13: Strain gauge readings for samples under 70\% preloading (a) (G1); (b) (G2)

It can be seen from Fig. 14 (a) that the strain at mid-span (strain gauge CG2 was affixed on the CFRP surface) for the columns strengthened with fibres oriented in the longitudinal 
direction reached the maximum value followed by descending until all elastic strain in the steel was released then continue without change. Depending on the preloading level, the maximum strain value was reached at a different time as previously described. It can also be noticed from this figure that the column tested under $70 \%$ preloading level had the highest value of strain compared to other columns. Similarly, strain gauge CG6 which was also mounted on the CFRP surface showed the same trend regarding the maximum strain value and time depending on the preloading level. The strain recorded by CG6 was negative because it was mounted in the region of the negative moment $(100 \mathrm{~mm}$ away the end of the column).

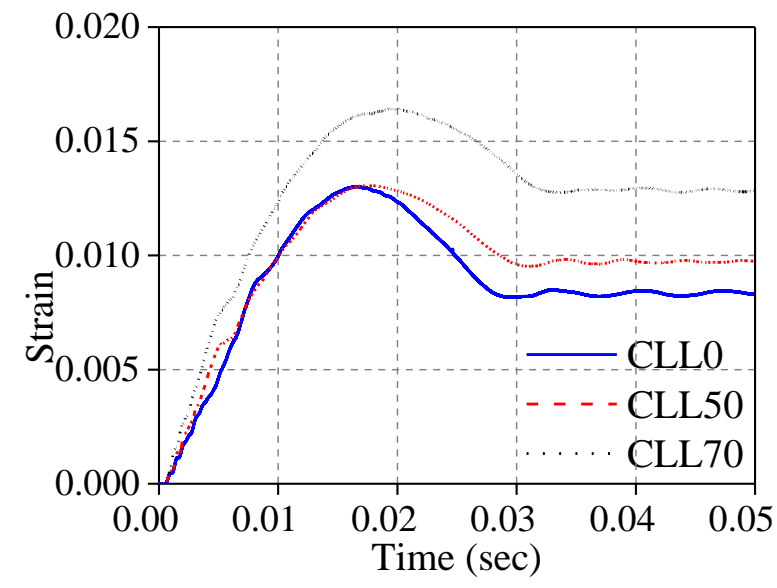

(a) $\mathrm{CG} 2$

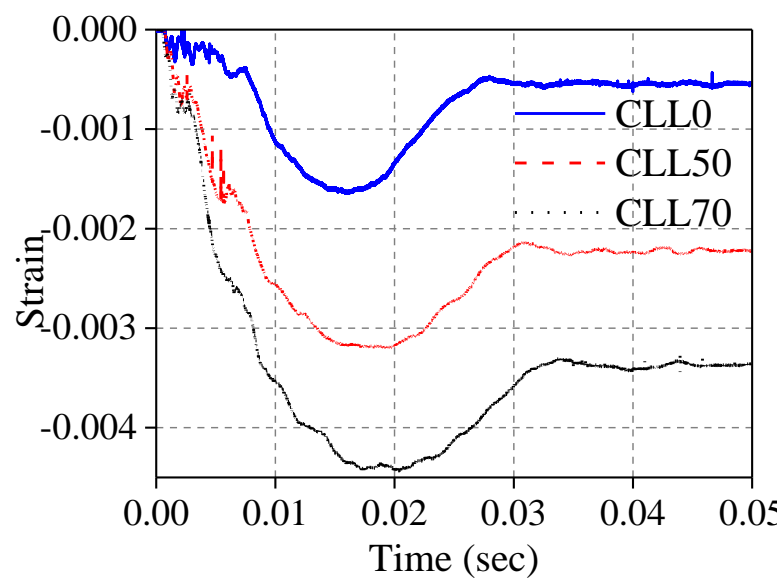

(b) CG6

Fig. 14: Strain gauge (CG2) and (CG6) for columns strengthened with fibres oriented in the longitudinal direction

\subsection{Axial force}

The axial force reduction depended on the reduction of the column height that was measured during the experiment using an LVDT. The final values for column height reduction (shortening) recorded before removing the axial load are listed in Table 2. It is clear from the table that the maximum shortening value was $7.5 \mathrm{~mm}$ for samples struck from $1 \mathrm{~m}$ height. 
Thus, the maximum reduction in the axial force can be predicted depending on the disc springs' stiffness. The values for the final axial force reduction are also listed in Table 2. It can be concluded from the table that the maximum reduction in the axial force was less than $12 \%$ of the initial axial force value. This value seems acceptable compared to other experiments that were undertaken using the same technique. For instance, the maximum reductions in the axial force compared to the initial applied force were $11 \%$ and $14 \%$ for the experiments conducted by Zeinoddini et al. [15] and Aghdamy [20] respectively. However, it should be noted that the $11 \%$ reported by Zeinoddini et al. [15] was not for the maximum applied axial force.

Table 2: The reduction of the axial force

\begin{tabular}{|l|l|l|l|l|}
\hline No. & Specimen & Preloading level $(\%)$ & Shortening $(\mathrm{mm})$ & Axial force reduction \% \\
\hline 1 & C50 & 50 & 4.8 & 10.7 \\
\hline 2 & C50B & 50 & 4.5 & 10.0 \\
\hline 3 & CLL50 & 50 & 3.8 & 8.5 \\
\hline 4 & CTT50 & 50 & 3.5 & 7.8 \\
\hline 5 & CLT50 & 50 & 3.2 & 7.1 \\
\hline 6 & C70 & 70 & 7.5 & 11.9 \\
\hline 7 & CLL70 & 70 & 4.8 & 7.6 \\
\hline 8 & CTT70 & 70 & 5.3 & 8.4 \\
\hline 9 & CLT70 & 70 & 3.9 & 6.2 \\
\hline
\end{tabular}

\subsection{Impact energy}

The energy time history of all samples tested with $70 \%$ preloading level are shown in Fig. 15. It can be seen from this figure that the overall shape of the energy time history for all samples was approximately identical and can be divided into two parts where the first part represents the increase in the absorbed energy with time until reaching the maximum value, while the second part starts to represent the rebound energy. It can also be concluded from this figure that the maximum absorbed energy in each sample was varied because of the external work applied on the axial direction. For example, the axial displacement (shortening) (see Table 2) for C70 was higher than the corresponding value for CLT70 when the axial force was almost 
constant. Thus, the sample having higher impact resistance absorbed less energy. This phenomenon did not appear in previous work such as Chen et al. [21] because no axial force was applied, the authors intend to investigate this further in a future study using finite element simulations.

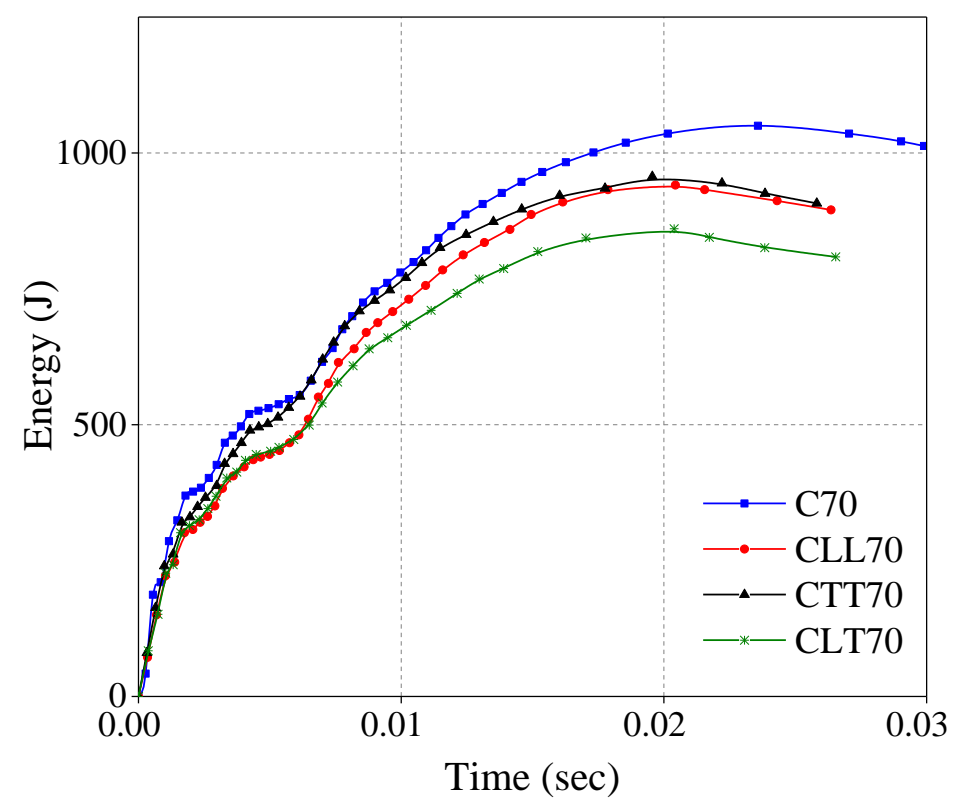

Fig. 15: Absorbed energy for samples tested with $70 \%$ preloading

Fig. 15 also demonstrates that most of the impact energy was absorbed in the plateau stage as presented in Section 6.1.2 when in the first stage (initial peak stage) about 13\% of the impact energy (from 0 to $0.002 \mathrm{sec}$ ) was absorbed while the rest of the energy was absorbed in the second stage (plateau stage).

\section{Conclusion}

The main aim of testing these samples was to investigate experimentally the impact behaviour of CFRP strengthened steel columns under different preloading levels and examine the effect of CFRP configurations. The following conclusions can be drawn based on the experiments presented in this paper: 
- CFRP can be effective in enhancing the impact resistance of structural steel compression elements. One of the beneficial effects of the CFRP in the current experiment is the ability to minimise the local buckling of the hollow steel section in the impact zone by using fibres oriented in the transverse direction.

- The effects of preloading level are significant. With an increase of the preloading level, the impact duration and residual lateral displacement increase while the plateau (mean impact force) decreases.

- As would be expected intuitively, of the three investigated CFRP strengthened configurations examined in this study, the strengthening configuration with fibres oriented in both longitudinal and transverse directions (i.e. the CLT configuration) resulted in the best impact resistance in terms of a higher sustained impact force (plateau) compared to other strengthened columns.

\section{Acknowledgments}

Our thanks to the Ministry of Higher Education and Scientific Research in Iraq for funding this research. The authors wish to acknowledge the technical staff in the School of Mechanical, Aerospace and Civil Engineering, University of Manchester, for facilitating the experimental work.

\section{References}

[1] BSI. BS EN 1993-1-1: Eurocode 3: Design of steel structures - Part 1-1: General rules and rules for buildings. London: British Standards Institution, 2005.

[2] Colombi P, Poggi C. An experimental, analytical and numerical study of the static behavior of steel beams reinforced by pultruded CFRP strips. Composites Part B: Engineering 2006;37:64-73.

[3] Deng J, Lee MM. Behaviour under static loading of metallic beams reinforced with a bonded CFRP plate. Composite Structures 2007;78:232-42.

[4] Shaat A, Fam A. Axial loading tests on short and long hollow structural steel columns retrofitted using carbon fibre reinforced polymers. Canadian Journal of Civil Engineering 2006;33:458-70. 
[5] Kim YJ, Brunell G. Interaction between CFRP-repair and initial damage of wide-flange steel beams subjected to three-point bending. Composite Structures 2011;93:1986-96.

[6] El Damatty A, Abushagur M, Youssef M. Experimental and analytical investigation of steel beams rehabilitated using GFRP sheets. Steel and Composite Structures 2003;3:421-38.

[7] Gillespie J, Mertz D, Edberg W, Demitz J, Kasai K, Hodgson I. Rehabilitation of steel bridge girders: large scale testing. Proceedings-American Society for Composites, New York, 1 October 1996. p. 231-40.

[8] Edberg W, Mertz, D. and Gillespie Jr., J. Rehabilitation of steel beams using composite materials. Proceedings of the Materials Engineering Conference, Materials for the New Millennium ASCE, Washington, 10-14 November 1996. p. 502-8.

[9] Al-Zubaidy HA, Zhao X-L, Al-Mahaidi R. Dynamic bond strength between CFRP sheet and steel. Composite Structures 2012;94:3258-70.

[10] Al-Zubaidy HA, Al-Mahaidi R, Zhao X-L. Experimental investigation of bond characteristics between CFRP fabrics and steel plate joints under impact tensile loads. Composite Structures 2012;94:510-8.

[11] Al-Zubaidy HA, Al-Mahaidi R, Zhao X-L. Finite element modelling of CFRP/steel double strap joints subjected to dynamic tensile loadings. Composite Structures 2013;99:4861.

[12] Alam MI, Fawzia S. Numerical studies on CFRP strengthened steel columns under transverse impact. Composite Structures 2015;120:428-41.

[13] Kadhim M, Wu Z, Cunningham L. FE modelling of CFRP strengthened steel members under impact loads. Proceedings of the 24th UK Conference of the Association for Computational Mechanics in Engineering, Cardiff, 31 March- 01 April 2016. p. 343-6.

[14] Kadhim M, Wu Z, Cunningham L. Modelling impact resistance of polymer-laminated steelwork. Proceedings of the Institution of Civil Engineers-Engineering and Computational Mechanics 2017;170:7-24

[15] Zeinoddini M, Parke G, Harding J. Axially pre-loaded steel tubes subjected to lateral impacts: an experimental study. International Journal of Impact Engineering 2002;27:669-90.

[16] Al-Thairy H. Behaviour and design of steel columns subjected to vehicle impact: University of Manchester, 2012.

[17] Shaat AAS. Structural behaviour of steel columns and steel-concrete composite girders retrofitted using CFRP [Ph.D thesis]: Queen's University, 2007.

[18] Huntsman. Structural adhesives aerospace adhesives araldite 420A/B. Switzerland: Datasheet, Huntsman Advanced Materials GmbH, 2009.

[19] Wang R, Han L-H, Tao Z. Behavior of FRP-concrete-steel double skin tubular members under lateral impact: Experimental study. Thin-Walled Structures 2015;95:363-73.

[20] Aghdamy S. Concrete-filled double skin tube columns subjected to lateral impact loading: Experimental and numerical study: Queensland University of Technology, 2016.

[21] Chen C, Zhao Y, Li J. Experimental Investigation on the Impact Performance of Concrete-Filled FRP Steel Tubes. Journal of Engineering Mechanics 2014;141:04014112. 